Ernst E, Pittler MH, Stevinson C, et al, editors. The Desktop Guide to Complementary and Alternative Medicine:An Evidence-Based Approach. St Louis: Mosby, 2001.

\section{The Desktop Guide to Complementary and Alternative Medicine}

an endence-based apprasch

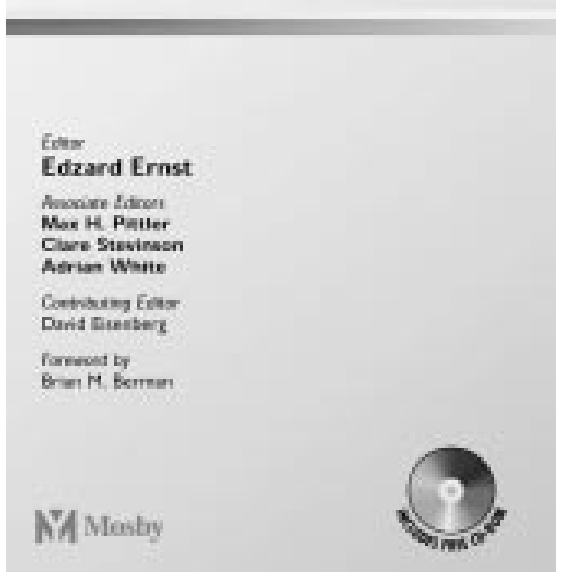

Ratings

Methods: $\star \star \star \star \succsim$

Clinical usefulness: $\star \star \star \star \star$
The Desktop Guide to Complementary and Alternative Medicine: An Evidence-Based Approach can be purchased online at http://www.harcourthealth.com fcgi-bin/displaypage.pl?isbn=0723432074 for US $\$ 34.95$. The table of contents and sample entries can be viewed at http://www.harcourt-international.com/ ernst/default.cfm.
More than $\$ 25$ billion is spent annually on complementary and alternative medicine (CAM) treatments in the USA, which indicates their popularity with the public. ${ }^{1}$ Increasingly, healthcare providers are being confronted with patients who are using these alternative treatments, and the providers have to determine their potential benefits and harm. In light of this trend, The Desktop Guide to Complementary and Alternative Medicine: An Evidence-Based Approach is a welcome new resource. This book has the ambitious objective of summarising a wide range of CAM interventions and of providing information on whether evidence exists to support their application. It also seems to be aimed at both healthcare providers and consumers.

The Desktop Guide to Complementary and Alternative Medicine is divided into 6 sections and includes a CD-ROM version. Section I, "Using this book," provides a useful summary of the organisation of the book and the methods used to summarise research. Section II, "Diagnostic methods," describes several CAM diagnostic techniques and the evidence supporting their use. Section III, "Therapies," provides an overview of such CAM disciplines as chiropractic, homoeopathy, and naturopathy, including evidence supporting their application. Section IV, "Herbal and non-herbal medicine," provides a summary of the clinical evidence supporting the use of herbal and non-herbal medicines and their potential harm. Section V, "Conditions," is perhaps the most useful to readers because it summarises evidence for the effectiveness of CAM interventions organised by healthcare condition (eg, the effectiveness of several CAM treatments for HIV and AIDS). This section is the most thorough in evidence presentation and provides summary tables of the evidence for each health condition. It also highlights critical pieces of evidence and gives a visual summary of the weight of evidence, direction of the evidence, and the potential harm of the product. Section VI, "General topics," examines several aspects relating to CAM, including legal, safety, and economic issues.

The editors of The Desktop Guide describe comprehensive techniques for summarising and appraising information. A broad search strategy of 4 medical databases is provided in the appendix. The editors state that they rely primarily on evidence compiled in systematic reviews. They have attempted to balance provision of detailed references and evidence with readability. To assist with this, they use a simplified scoring system for grading the weight (level, quality, and volume) and direction of the evidence. The book lacks information on how it will be kept up to date, although the editors state their intention to do so. Keeping this resource up to date is particularly important given the increasing volume of research evidence that examines the effectiveness of CAM and the potential for interactions and harm of the treatments.

The editors state that a precautionary approach has been taken in reviewing the specific CAM treatments. Unless evidence to support the safety of a substance exists, it is not considered risk free. This cautious approach is warranted given the absence of the strict regulations that govern much of conventional medicine. However, even this strict approach is not fail safe because of the variability in production and manufacturing of many of the CAM products. For example, at the time of writing this review, regulatory agencies were investigating a potential link between the use of kava containing substances and serious liver toxicity. ${ }^{2}$ In the book, kava is considered to be generally safe because of the absence of documented harm at the time of publishing.

In reviewing this book, I took the perspective of a traditional healthcare provider who desires to learn more about the field of CAM. From this perspective, the book met most of my expectations. I believe that readers will be surprised at the number of studies done on alternative medicine, although many are small, short, and of suspect quality. The Desktop Guide to Complementary and Alternative Medicine provides interesting information on specific treatments that have good evidence for benefit (eg, hawthorn for congestive heart failure) as well as other widely used treatments for which evidence exists showing lack of benefit. The book is easy to use and the CD-ROM allows for quick searches for specific CAM products.

This book is a valuable resource for healthcare providers seeking to acquaint themselves with the "black box" of CAM, provided the reader exercises caution and judgment.

KUMANAN WILSON, MD

University Health Network, University of Toronto, Toronto, Ontario, Canada

1 Eisenberg DM, Davis RB, Ettner SL, et al. Trends in alternative medicine use in the United States, 19901997: results of a follow-up national survey. JAMA 1998;280:1569-75.

2 Kava linked to liver toxicity. National Center for Complementary and Alternative Medicine. (http://nccam.nih.gov/fcp/kava/kava.htm). Accessed 2002 March 7. 